\title{
HUMOR, HUMORISTAS E PROBLEMAS DE TOPIA DISCURSIVA
}

\author{
Rony Petterson Gomes do Vale* \\ Universidade Federal de Viçosa \\ Centro de Ciências Humanas e Artes \\ Departamento de Letras \\ Viçosa, MG, Brasil
}

\begin{abstract}
Resumo: Partindo do conceito de campo discursivo e da história do humorismo, traçamos, em linhas gerais, o caminho do humor das entrelinhas da literatura para sua institucionalização enquanto campo do humor. Procuramos evidenciar, primeiramente, como o humor passa de característica estilística de alguns escritores e poetas para certa regulamentação da profissão de humorista junto aos campos do jornalismo e da publicidade. Em um segundo momento, verificamos que o conceito de VRBANITAS, que regulamenta os usos do riso no discurso, pode ser percebido a partir das disputas de posicionamento entre os sujeitos dentro do campo do humor, que se diferenciam de acordo com a concepção adotada sobre o que é fazer humor e fazer rir, e com os modos de adaptação às constantes mudanças sociais, às novas formas de mídias e ao movimento politicamente correto.
\end{abstract}

Palavras-chave: Humorismo brasileiro. Campos discursivos. Análise do Discurso. Método confuso. Politicamente correto.

\section{INTRODUÇÃO}

Se partirmos da ideia de que "todo discurso se constrói na intersecção entre um campo de ação, lugar de trocas simbólicas organizado segundo relações de força [...], e um campo de enunciação, lugar dos mecanismos de encenação da linguagem" (CHARAUDEAU, 2006b, p. 52 - grifos nossos), podemos, então, assumir que o conceito de topia discursiva não somente diz respeito a "um espaço do que é dizível em uma sociedade" (MAINGUENEAU, 2010, p. 170), mas também a um espaço do que é dizível dentro de um dado campo de discurso. Isto é, embora o sujeito do discurso possua certa margem de manobra (as estratégias discursivas) dentro dos mais diversos contratos de comunicação, ainda assim seu discurso é regulamentado por certas pressões do campo discursivo ao qual ele, o sujeito, está, de certo modo, subordinado.

Como ensina Possenti (2010), um campo discursivo estabelece certas regras que, por isso mesmo, podem ser consideradas como constituivas do próprio campo, diferenciando-o de outros dentro de uma dada sociedade. Com efeito, essas regras regulamentam, além da circulação e da edição dos textos, a própria produção discursiva, estabelecendo, por vezes, certos formatos genéricos e textuais. Todavia, ainda que esses procedimentos apontem para uma relativa homogeneidade, os campos discursivos são

\footnotetext{
* Professor Adjunto I. Doutor em Linguística do Texto e do Discurso. Área: Análise do Discurso. E-mail: ronyvale@ufv.br.
} 
internamente heterogêneos, ou seja, são lugar de um "jogo" de equilíbrio instável "no interior do qual interagem diferentes 'posicionamentos', fontes de enunciados que devem assumir os embates impostos pela natureza do campo, definindo e legitimando seu próprio lugar de enunciação" (MAINGUENEAU, 2010, p. 50).

Assim sendo, podemos supor que um campo do humor parece estabelecer, como propriedade constitutiva, um lugar de posicionamentos fortemente marcado por uma permanente instabilidade. Isso porque, embora o campo do humor apresente, no decorrer da história, uma tendência a se configurar, de modo semelhante ao campo literário, "de formas específicas no que diz respeito à edição, à circulação, à escolarização, à crítica, à demanda por leitores, à consagração do autor" (POSSENTI, 2010, p. 173), o discurso humorístico (doravante, DH) necessita, devido a suas propriedades mimotópicas ligadas à imitação de gêneros e de textos, que o próprio sujeito-humorista procure romper a todo momento as regras (também instáveis) do campo, fazendo com que esse último se mantenha, desse maneira, permanentemente instável.

Desse modo, nas seções que se seguem, procuramos discutir essa instabilidade do lugar ou topia do humorista em relação a certos campos discursivos (literário, jornalístico, publicitário... humorístico), buscando, com isso, verificar como o humor, saindo das soleiras da literatura, fez surgir, a partir das inovações tecnológicas dos séculos XX e XXI, certos "profissionais do riso" (humoristas, comediantes, "risistas" etc.) que procuram delimitar o próprio espaço dentro do campo discursivo do humor, colocando em debate o que é ser um humorista.

\section{HUMOR NAS ENTRELINHAS DA LITERATURA}

Como se sabe, vários foram os motivos que teriam proporcionado o surgimento do humorista na Europa e, em especial, na Inglaterra do século XVIII ${ }^{1}$. Entre esses

\footnotetext{
${ }^{1}$ Entre esses fatores podemos citar, por exemplo: i) uma forte reação da intelligentsia europeia contra o burlesco vulgar (baixo, subversivo e grosseiro, ligado à dimensão corporal) que atingia a linguagem por meio de termos chulos, populares e coloquiais (SKINNER, 2002), sendo proposta, juntamente com um refinamento de costumes, uma purificação da linguagem (da elite, por certo), tomada, agora, como uma barreira social que deve evitar a "infiltração da ralé na melhor sociedade" (MINOIS, 2003, p. 409); ii) o surgimento, no final do século XVII e no início do século XVIII, de reflexões e de "elaboradas teorias" a respeito do humor enquanto característica psicossocial do homem, baseada, ao mesmo tempo, no riso, na melancolia, no pessimismo e no distanciamento; porém, em muito diferente da troça, da idiotice e da zombaria, tomando o humor, a partir de então, ares de categoria estética e psicológica, a ser observada (e analisada) no estilo de pensadores, escritores e poetas (ESCARPIT, 1972, p. 8-9); iii) uma significativa especialização da imprensa, proporcionada por sensíveis avanços na forma de impressão de material escrito (litografia) e de imagens (litogravura), institucionalizando-se, desse modo, como meio de comunicação de massa e, com base numa relativa liberdade, assumindo o riso (e nas suas formas reduzidas), a caricatura e a charge como fortes aliados nas questões gerais de atratividade dos periódicos (o humor como meio de sedução) (SANTOS, 2012, p. 43), de denúncia das mazelas sociais e de crítica aos sistemas estabelecidos; e iv) o advento do Romantismo que pregava uma reação aos preceitos da retórica e às leis externas da tradicional educação literária desenvolvidas a partir do Classicismo (PIRANDELLO, 1996, p. 52), dando, assim, livre curso ao sentimento, ao poeta que podia, agora, utilizar, espontaneamente, a sua inclinação para o humor e para o riso, sem passar pelo critério da imitação estabelecido pelos modelos retóricos.
} 
motivos, merecem destaque os avanços tecnológicos pelos quais passou a imprensa. Esses avanços, como já comentamos, fizeram com que o texto impresso se tornasse mais comum, passando de objeto de luxo (no caso do livro) a meio de comunicação de massa em forma de panfletos, folhetins e almanaques. Segue que o aumento de tiragens, assim como a maior presença de imagens (litografia/litogravura), fizeram com que outros campos discursivos abrissem concorrência com o campo literário. Assim, os campos midiático e publicitário passam a conviver com a grande literatura, buscando progressivamente uma especialização de cada setor.

Em meio a esses campos discursivos, o humorista começa a desenvolver sua "arte" e, como sugere Pirandello (1996), se iniciam, também, as discussões em torno do sentido do que é ser humorista. Mennucci (1923), por exemplo, nos diz que o humorista é aquele escritor que carrega como marca de estilo a busca pelo desnivelamento dos assuntos de que trata. Com efeito, diferentemente do literato que

evita assumptos rasteiros e procura elevar mesmo aquelles de que accidentalmente cuida, alteando o tom da prosa [...]. O humorista está sempre em oposição ao assumpto. Quando são altos, foge aos ouropéis do estylo, rebaixa-os, tratando-os com maneiras por assim dizer corriqueiras [...]. Quando, ao contrário, eleva o tom da voz, é em assumpto banal. Tornar épicas as banalidades e banalizar os heroísmos, eis o grande processo dos humoristas. (MENNUCCI, 1923, p. 41)

No Brasil, no final do século XIX e início do XX, essa diferenciação entre literatos e humoristas também afetou drasticamente o campo literário, onde, aparentemente, "a preocupação de todo escritor era parecer ser grave e severo. O riso era proibido" (MACHADO, 1940 apud GARCIA, 2010 p. 127). Nesse contexto, coube à imprensa e à publicidade absorver os escritores e os poetas que fugiam à regra. No entanto, os humoristas começam a travar uma batalha pelo reconhecimento e pela aceitação do público. Reconhecimento e aceitação que, até aquele momento, se restringiam somente aos literatos.

Um caso interessante é o de Mendes Fradique. Sua produção humorística, de acordo com Lustosa (2004, p. 17), atingiu grande sucesso comercial, a citar a sua História do Brasil pelo método confuso (HBMC) que teve sete edições durante a década de 1920, sendo considerada "até hoje o livro brasileiro mais completo em recursos humorísticos que se conhece". Rompendo com a historigrafia tradicional, a $H B M C$ assume características estruturais e temáticas bastante próximas das tendências ${ }^{2}$ modernistas presentes em outras obras do mesmo período, como, por exemplo: a Poesia Pau-Brasil de Oswald de Andrade; o Macunaíma de Mário de Andrade; e a História do Brasil $^{3}$ de Murilo Mendes. Apesar disso, como ressalva Lustosa, Fradique,

\footnotetext{
2 Essas tendências, como assegura Candido, tinham como característica comum a presença de "mais humour, mais ousadia formal, elaboração mais autêntica do folclore e dos dados etnográficos, irreverência mais consequente, produzindo uma crítica mais profunda.” (CANDIDO, 2006, p. 129)

${ }^{3}$ De acordo com Saliba (2002, p. 130), esse livro, único de caráter cômico da obra de Murilo Mendes, foi renegado pelo próprio autor, uma vez que não seguia o teor geral de sua obra. Como afirma Bosi (2012, p. 468-478), Murilo mostra em sua obra uma mudança de engajamento. No período inicial de produção literária, teria assumido um posicionamento mais político, no qual seus poemas, anteriores a 1934 (ano de
} 
diferentemente dos escritores citados, foi esquecido pela posteridade, restringindo-se à referências escassas sobre sua arte do desenho (caricaturas) e sua contribuição em periódicos humorísticos como a Revista Quixote (1917) e o jornal O Macaco (1939).

É importante notar que o próprio Fradique parecia antever esse "esquecimento" como uma espécie de condenação por cometer livros humorísticos (FRADIQUE, 2004, p. 253). No capítulo 41 da sua $H B M C$ intitulado "Remorsos", o autor simula ter sido obrigado pelos editores a ler as provas de seu livro. Essa leitura, que Fradique considera quase um suplício chinês, faz com que o autor entre num estado de aparente loucura, ao que se segue um transe parecido com os delírios de Brás Cubas. Em meio a fantasmas, aparentemente as personalidade históricas que Fradique satirizou, surge Dante Alighiere, convidando-o a um passeio até o "inferno"... Niterói. Ao chegar na ilha, Fradique se depara com um prédio em cujo portal de entrada lia-se: Hospício Nacional dos Alienados. Depois de uma visita às dependência desse "inferno", Fradique pede a Dante que lhe mostre o "paraíso". Pedido a que Dante consente, mas adverte a Fradique: "Olha Mendes lá está o Paraíso. Contenta-te em lobrigá-lo à distância, que aquilo não é para o bico de escritor mambembe." (FRADIQUE, 2004, p. 256).

Ao que tudo indica, com "mambembe", Dante categorizava toda uma espécie de escritor/poeta que se envereda pela mediocridade e pela arte do cômico e do riso. Tanto é assim que Fradique (1925 apud SALIBA, 2002, p. 134) afirma que nenhuma linha do que escrevia escapava ao título de "piada" e ao methodo confuso ${ }^{4}$, ou seja, a máscara humorística o acompanha mesmo em seus escritos sem intenção cômica/humorística. Sobre essa "máscara", Saliba (2002) salienta que:

O humorista não era reconhecido socialmente, e eles próprios [os humoristas] tinham dificuldade em reconhecer-se como humoristas. O mais notável é que quando designados publicamente como humoristas, o rótulo colava-se a eles como a máscara do palhaço e não havia meio de tirá-la. (SALIBA, 2002. p. 133-134).

Muito embora, nesse mesmo contexto, a "anedota" gerasse um certo sucesso perante o público, ela não apresentava valor estético nenhum, não trazia status de literato para o escritor "mambembe". Assim, não é de se espantar que alguns humoristas dessa época, como, por exemplo, Bastos Tigre e Emílio de Meneses, procurassem escrever poesia séria no formato parnasiano. Além disso, numa tentativa de se esquivar dessa máscara humorística, o uso de pseudônimos passa a ser uma estratégia discursiva

sua conversão ao catolicismo), "fazem o giro piadístico de um Brasil morno e provinciano e ecoam a maneira inicial de Oswald e Mário de Andrade" - data dessa mesma época a publicação da sua História do Brasil. Num segundo tempo, ainda de acordo com Bosi, o autor passaria a um posicionamento mais religioso ou, esteticamente falando, a um posicionamento de "crente surrealista", no qual sua obra tende para uma linguagem religiosa, focada na busca fervorosa pelo paraíso cristão.

${ }^{4} \mathrm{O}$ Método Confuso tem suas origens na publicação póstuma da obra do escritor Luís Delfino, feita por seu filho, Thomaz Delfino. Segundo Busatto (1984, p. 274), o fato de essa publicação ter se dado de modo disperso, em vários volumes, e sem uma ordem ou um critério, impossibilitou o acompanhamento da evolução estética da obra de Luís Delfino. Para Lustosa (1993, p. 111-112), esse método é a grande característica do estilo de Mendes Fradique que, invadindo "o espaço editorial através de informações falsas ou de deslocamentos de fatos, datas, personagens, biografias, notas de rodapé, prefácios etc.", faz refletir, crítica, satírica e humoristicamente, sobre os mais diversos temas na sociedade brasileira. 
não somente dos humoristas ${ }^{5}$, mas também dos literatos que, a exemplo de Olavo Bilac, Guilherme Passos, Martins Fontes entre outros, por vezes, escreviam quadras humorísticas e slogans, digamos, bem-humorados para a publicidade da época. Nesse caso, Lustosa (1993, p. 69) sugere que a irreverência, marca do humorista, dificilmente poderia caber "na atitude sublime do poeta, no seu arrebatamento rumo ao etério e outras formas de que se fazia até então", uma vez que essa irreverência "era uma moeda social, sem dúvida, pois dava prestígio e poder, mas não era reconhecida como expressão de arte, [de] valor estético em si. Fazia-se apenas consumo interno. Seu papel era divertir e deleitar a sociedade". Ou seja, a linguagem do humor, marcada pela irreverência e pela linguagem do cotidiano, não tinha lugar na grande literatura.

Mesmo assim, como ressalta Saliba (2002, p. 142-144), os humoristas continuavam na busca pelo reconhecimento da instituição que, nessa época, representava a referência da intelligentsia brasileira: a Academia Brasileira de Letras $(\mathrm{ABL}) . \mathrm{O}$ "escritor mambembe", podemos dizer, ao mesmo tempo que ironiza a ABL, atacando seus membros", quer "partilhar daquele grupo de homens cultos, mas percebe que paira sobre seu nome, como uma sombra, a pecha de "humorista". Assim, com lemas como "A Troça por princípio, a Pilhéria por base, o Riso por fim." (TIGRE, 1905 apud SALIBA, 2002, p. 136), dificilmente os humoristas seriam eleitos para uma cadeira na ABL, cabendo a eles, "espremidos entre o teatro ligeiro e o jornalismo de ocasião, num precário equilíbrio para agradar, a todo custo, o público das revistas ilustradas" habitar somente "a zona suburbana' das letras brasileiras" (SALIBA, 2002, p. 133). Pensemos: a ABL, motivo de admiração e de ódio dos humoristas, seria, então, o "paraíso" que Dante mostrara a Fradique?

\section{EM DEFESA DA PROFISSÃO: HUMORISTAS VERSUS RISISTAS}

Os avanços tecnológicos do século XX não tardaram a modificar a condição de profissional do riso na socidade brasileira. A popularização do cinema, a disseminação do rádio e, em meados do século, a criação da TV preparam o terreno para que os profissionais do riso se concentrassem na defesa do humor como um produto de consumo que movimenta dinheiro e gera empregos. Com isso, o campo discursivo do humor começa a se organizar e, podemos dizer, as questões éticas em torno do riso, fundamentadas na VRBANITAS $^{7}$, passam a ser um critério de diferenciação dos

\footnotetext{
5 São exemplos de humoristas que se utilizaram desse recurso nesse período: José Madeira de Freitas (Mendes Fradique); Bastos Tigre (D. Xiquote); Aparício Torelly (Barão de Itararé); Alexandre Marcondes Machado (Juó Bananére), para citar os principais.

${ }^{6}$ Podemos citar, por exemplo, Masucci (1958, p. 12-13) que, com uma ponta de desdém, assim se refere à ABL e a seus membros: "ACADÊMICO - Escritor pôsto em quarentena."

${ }^{7}$ Conceito retórico que, remontando a Cícero e Quintiliano, prescreve, entre outras coisas, as vantagens e as desvantagens do uso do riso pelo orador. Entre as vantagens, podemos citar, por exemplo, a amenização das situações de tensão no fórum e na assembleia e a desarticulação das estratégias discursivas do adversário. Já entre as desvantagens, os latinos são categóricos: não se deve utilizar o riso (i) contra aqueles que são amados nem contra aqueles acometidos por doença ou por qualquer outro infortúnio, ou seja, utiliza-se o riso somente contra os vícios, mas não contra as torpezas graves, o que pode levar o auditório à comiseração e não ao riso; não se deve fazer (ii) uso de obscenidades ou de
} 
profissionais do riso dentro desse campo. Nesse ínterim, são esclarecedoras as palavras do humorista Ziraldo para quem:

O Humor é uma atividade econômica. Primeiro a Imprensa e depois todo o desenvolvimento dos meios de comunicação trouxe o humor das entrelinhas das obras literárias e das insinuações dos quadros dos grandes mestres - Miguel Ângelo fêz Humor e Ironia na Capela Sistina - para o primeiro plano nas páginas dos jornais e periódicos e depois para o som do rádio e a imagem da televisão. A comunicação massificada necessitou do Humor para preencher suas novas formas de mensagens - a Propaganda também entrou na dança - e eis que eu tenho uma profissão, ainda não regulamentada pelo Ministério do Trabalho. Sou humorista. (PINTO, 1970, p. 27)

Desse modo, o humorista deixa de ser um escritor com certo espírito literário específico (satírico, cômico, espirituoso, irônico et similia) para se tornar uma profissão, com todos os problemas que isso pode acarretar como, por exemplo, a regulamentação do Ministério do Trabalho, o registro na carteira de trabalho, os acertos salariais etc. Nesse último ponto, Ziraldo é categórico: “com humorismo ninguém poderá sobreviver ou ganhar dinheiro, só se é pago para fazer rir" (PINTO, 1970, p. 36 - grifos nossos). Isso porque Ziraldo entende que o humor está ligado à defesa de uma "verdade", uma tese sobre o mundo, que desmonta as coisas para que outrem as veja mais claramente: "Tôda a vez que você ouvir uma história, parar e pensar assim: 'Ué, gente. Não é que é isso mesmo!?...' pode estar certo de que é a revelação que o humor contém que te faz exclamar assim. O Humor tem sempre uma verdade dentro" (PINTO, 1970, p. 29-30 grifos do autor).

Como podemos perceber, Ziraldo apresenta uma visão quase "romântica" que alia humor e "verdade" e, de certa forma, distancia o riso do humorismo. Essa é a base da sua diferenciação entre aquele sujeito do riso que é mestre na arte de fazer rir, que ganha dinheiro para fazer rir e cujo objeto de trabalho é especificamente fazer rir, daquele outro sujeito do riso que não somente faz rir, mas que faz algo mais como pensar, refletir, admirar o que está encoberto, isto é, faz ver coisas que, somente com o humor, seríamos capazes de evidenciar. Com efeito, para Ziraldo, "um cara que escorrega numa casca de banana e cai é cômico. A êste que pretende criar o riso continuará sendo naturalmente um humorista - chamaremos risistas [...]. Depois vêm os outros, tudo humorista" (PINTO, 1970, p. 35).

Da dicotoma humoristas vs. risistas proposta por Ziraldo, podemos inferir, também, um embate entre diferentes gerações de humoristas que gira em torno de um restabelecimento da essência do que seja o humor, o humorismos, a comédia, enfim, o fazer rir. Esse conflito entre diferentes posicionamentos é, como sugere Maingueneau (1999, p. 50), uma tentativa de retorno às "ideias primeiras" como, por exemplo, o Belo,

qualquer recurso que aproxime o orador do mimvs ou do bufão; e, por fim, (iii) não se deve utilizar dos GENERA RIDICVLORVM ("gêneros de ditos ridículos") quando esses beirarem ao ultraje, pois o riso custa caro e sua cota é a honra. Enquanto categoria descritiva na AD, a VRBANITAS tem o potencial de desvelar a adequação tanto do sujeito (representado pelo seu ethos prévio e discursivo) quanto do seu discurso às coerções sociais e sociodiscursivas previstas no contrato de comunicação do DH, o que faz da VRBANITAS uma categoria propriamente discursiva, pois, assim definida, "não se deixa reduzir a uma grade estritamente linguística, nem a uma grade de ordem sociológica ou psicossociológica" (MAINGUENEAU, 1999, p. 47 - tradução nossa). Mais detalhes sobre essa categoria, veja: Vale (2011). 
a Verdade, a Literatura, a Política, o Divino etc., que alguns poscionamentos dentro de um mesmo campo discursivo teriam desfigurado, esquecido ou subvertido. Nesse sentido, para Ziraldo, por exemplo, todo humorista pode vir a se tornar um risista, mas o contrário nem sempre é possível de acontecer, o que, de certo modo, afastaria Ziraldo e sua geração de todo um grupo de de humoristas e de comediantes que se estabeleceram nas "zonas suburbanas" da literatura, nos tempos áureos do rádio e nos primórdios da TV.

Essa diferenciação, como vimos, se deve, principalmente, às inovações tecnológicas que geraram outras formas de mídium e de finalidades aferidas ao humor nos meados do século XX. A questão que se coloca é que essas inovações não se estagnaram e, no final do século XX e início do XXI, acabaram por possibilitar o surgimento de novas formas de mídium (como, por exemplo, as TVs "fechadas", ou por assinatura, e, principalmente, a internet com a disseminação de vídeos caseiros com sketches humorísticos, de animações satíricas e de montagens cômicas em sites como, por exemplo, o Facebook e o Youtube) que viriam a gerar uma nova geração de humoristas que, nos dizeres de Veríssimo, "se livra da velha tradição do circo, do teatro de revista e da caricatura grotesca, como ainda se vê no Zorra Total. Independentemente, claro, dos gênios do velho estilo, como Chico Anysio" (VERISSIMO, 2013, p. 40). Na visão de Porchat $^{8}$ (apud MARTINHO, 2013, p. 65), a nova geração do humor brasileiro se adaptou a certas condições de recepção desenvolvidas na atualidade. Para esse humorista, o humor de hoje não é muito diferente do humor do passado, mas o "ritmo das pessoas" em relação ao humor mudou; logo, como atualmente estamos mais acelerados, é certo que o humor também deve seguir outro timing.

Por outro lado, Madureira9 (apud MARTINHO, 2013, p. 63) admite que esse "novo humor" é consequência de uma crise de criatividade humorística, resultante de uma nova forma de censura branca fundamentada no politicamente correto $^{10}$. Tal

\footnotetext{
${ }^{8}$ Fábio Porchat é humorista e um dos roteiristas do programa Zorra Total da Rede Globo de TV, além de participar da produção dos sketches humorísticos do canal Porta do Fundos do Youtube.

${ }^{9}$ Marcelo Madureira é humorista, um dos principais integrantes do grupo Casseta \& Planeta.

${ }^{10}$ Segundo Pondé (2012, p. 29-31), o movimento politicamente correto pode ser definido como "uma mistura de covardia, informação falsa e preocupação com a imagem". Ainda de acordo com autor, esse movimento tem sua origem num "ramo" do pensamento de esquerda americano que, a partir dos fins dos anos de 1960, assume uma espécie de programa político de defesa das minorias (negros, na década de 1960; gays, a partir da década de 1980), procurando desenvolver um "mal-estar" com relação ao "mau" tratamento dado a esses grupos na vida social comum. Assim, tal programa muda o foco da ação da esquerda da revolução pelo proletariado para uma acomodação do status quo desses grupos minoritários, em ascensão econômica e social, ao capitalismo, gerando, para esse fim, leis e políticas públicas que possibilitem a realização do processo. Atualmente, continua Pondé (2012, p. 31), o politicamente correto "se caracteriza por ser um movimento que busca moldar comportamentos, hábitos, gestos e linguagem para gerar a inclusão social desses grupos e, por tabela, combater comportamentos, hábitos, gestos e linguagem que indiquem uma recusa dessa inclusão". Especificamente em relação ao humor, Aubert (2013, p. 104) adverte que o que está em jogo é o próprio futuro do riso, uma vez que "o problema maior não é a liberdade de reclamar de algo que se considera ofensivo; a coisa complica é quando o politicamente correto vira lei e passa a comprometer a liberdade de expressão. Se esse ímpeto coercitivo não for refreado, ele poderá impedir, no limite, que qualquer cartum seja desenhado, que qualquer livro
} 
censura, ainda segundo Madureira, é responsável pelo estabelecimento de leis e de processos por difamação que, por detrás, não teriam somente objetivos moralistas a favor de minorias, mas também certas finalidades financeiras ${ }^{11}$ : "Essa patrulha do moralismo também tem fins lucrativos. Hoje fundar uma ONG em defesa dos anões caolhos gera dinheiro e é preciso justificar esse dinheiro. Essas representações são muitas vezes questionáveis, veem preconceito em tudo." (MADUREIRA apud MARTINHO, 2013, p. 63)

Somada ao politicamente correto, uma hipótese sugere que esse novo tipo de humor e essa nova geração de humoristas são resultados, em maior ou menor medida, da introdução da cultura norte-americana do stand-up no cenário humorístico brasileiro, que, de certo modo, proporcionou, na mente desses humoristas, o direito a certos excessos de liberdade discursiva fora do espaço dos palcos, como, por exemplo, a zombaria ofensiva e gratuita, a chularia, a excrementícia etc. Tas ${ }^{12}$ (apud HAMA, 2013, p. 98), por sua vez, acredita que o humor, por si mesmo, é que fornece tais licenças, pois, quando se joga com o humor, pode-se colocar as pessoas despidas; no entanto, admite: "sou muito mais processado hoje do que no regime militar, e por razões muito mais ridículas". Gentili ${ }^{13}$ (2012, p. 6) admite que nunca foi censurado na TV, "mas é óbvio que alguns temas são mais fáceis de se trabalhar no teatro".

Quanto a essas condições de produção impostas pela sociedade aos profissionais do riso, Madureira (apud XAVIER, 2011) é mais categórico: "quando você ofende alguém, é porque não houve graça, falhou”. Alvo de inúmeros processos por ofensa, Gentili (apud MARTINHO, 2013, p. 63) procura relativizar a questão, fundamentandose na história do humorismo brasileiro: "todo mundo fala de Chico Anysio e Jô Soares como se eles fossem santos, nesse sentido". [...] Mas eles faziam piadas sexistas, zoando homossexuais, raças e credos". De um ponto de vista, digamos, quantitativo, Tabet ${ }^{14}$ (2013, p. 20) assume que "o que vai salvar o humor da polêmica é ele ser engraçado, ser bom. Se for ofensivo, pode até ter alguém que ria, mas muita gente não vai rir. E o que a gente busca é isto: quanto mais gente rindo melhor".

Como podemos depreender do exposto até aqui, os posicionamentos e as discussões sobre o que é e como se faz humor alternam de acordo com as condições de produção do discurso humorístico (doravante, DH) e, por que não dizer, das condições de mercado criadas por uma sociedade. Assim, no que se segue, procuramos ver como o

seja escrito, qualquer filme seja filmado [...]. O politicamente correto, à solta e legalizado, acabará por impedir, no fim das contas, o riso."

${ }^{11}$ Em relação aos processos do programa CQC, Tas (apud HAMA, 2013, p. 100) acredita que a questão não somente gira em torno de objetivos lucrativos, mas também que ela possui motivação política, pois, segundo o humorista, o objetivo de se processar o programa seria evitar que, na campanha eleitoral, perguntas "pontiagudas" sejam feitas a determinados candidatos de conduta política e social duvidosa.

12 Marcelo Tas é ator, humorista, apresentador e diretor do programa humorístico CQC da Rede Bandeirantes de TV.

${ }^{13}$ Danilo Gentili é humorista stand-up, fez parte do programa CQC e, atualmente, divide, com o Programa do Jô, o horário nobre dos programas no molde talk-show com o seu Agora é tarde, pela Rede Bandeirantes de TV.

${ }^{14}$ Antônio Tabet é humorista, blogueiro e criador do site humorístico Kibe-Loco. Atualmente, é um dos responsáveis pelo canal de sketches Porta dos Fundos. 
DH reflete tais condições e, ao mesmo tempo, como os humoristas, influenciados pela cultura stand-up e pelo politicamente (in)correto, "jogam" com as coerções sociais e sociodiscursivas estabelecidas, atualmente, na sociedade brasileira.

\title{
4 HUMORISTAS E O POLITICAMENTE (IN)CORRETO: DO STAND-UP AO MARKETING PELO MÉTODO CONFUSO
}

Fruto da escola americana de humor, o stand-up é um tipo de espetáculo apresentado por um único humorista (one man show) de cara limpa (sem maquiagem) e em pé (por isso, stand-up), e, normalmente, realizado em teatros, cinemas, casas noturnas ou bares. Na maioria dos casos, não são utilizados nenhum dos artifícios da arte dramática, como, por exemplo: cenário, figurino, sonoplastia, trilha sonora, personagens, entre outros. No palco, o humorista tem grande liberdade para dizer aquilo que lhe vem à mente, utilizando-se de vários recursos (verbais e miméticos) e de quaisquer temas (política, sexo, excrementícia, religião, casamento etc.), contanto que faça rir. Enquanto gênero, algumas regras são estabelecidas como a não interpretação de personagens e, principalmente, a não utilização de piadas ou de "causos" já conhecidos, pois, como afirma Gonzaga ${ }^{15}$, “a força está no texto. Muitas vezes, o público aplaude mais uma observação inteligente, com que ele se identifica, do que o engraçado" (apud MENDONÇA, 2007). No entanto, essas regras, como ridiculariza Marrom ${ }^{16}$, nem sempre são obedecidas e, por vezes, também servem de motivo de piada:

\begin{abstract}
Falá pra vocês o que é o stand-up: o stand-up é isso aqui... a pessoa chega aqui e fala o que tiver na cabeça dela, importante que seja engraçado... que arranque risada, não é isso? Isso é o stand-up. Mas tem algumas regras. Sabe que não pode ter um cenário [...], por exemplo, se eu colocar um peruca, deixa de ser stand-up e passa a ser personagem. Isso é uma pequena aula que eu tô dando pra vocês, viu... Quiser botar um jaleco branco, por exemplo, e quiser fazê um médico alemão... não! alemão, não... médico. Ah... não pode, sabia? $\mathrm{E}$ uma das coisas que é abominável no meio stand-up é contar uma piada que já existe. Isso mata qualquer um que é do meio stand-up, mata de raiva, não pode! É regra. Mas, como diz no ditado, que "quando não caga na entrada, caga na saída"... eheheh... Eu vou sair com uma piada que já existe. E que se foda o stand-up!... E suas regras. ${ }^{17}$
\end{abstract}

Autoderrisão, uso de termos chulos, quebra das coerções do gênero: tudo é matéria para fazer rir. No stand-up, não há a proteção da máscara do palhaço ou da personagem sob a qual o ator cômico poderia se esconder: "não fui eu quem disse aquelas barbaridades; foi a personagem". O humorista está totalmente exposto: seu ethos prévio e discursivo se consubstanciam, e o seu discurso, quando relatado pela

${ }^{15}$ Cláudio Torres Gonzaga é humorista e, na época da matéria, era redator chefe do programa do Zorra Total da Rede Globo de TV.

${ }^{16}$ Marcelo Marrom é um humorista stand-up cuja principal característica discursiva é a utilização da autoderrisão pelo fato de ser negro. Com isso, Marrom é alvo de inúmeros processos legais por prática preconceituosa contra brasileiros afrodescendentes.

17 Comedy Central Apresenta Stand-up com Marcelo Marrom. Disponível em: <https://www.youtube. com/watch?v=014FjRwzFFk>. Acesso em: 14 mar. 2013. 
mídia, por vezes, não é devidamente contextualizado, o que resulta em dificuldades - às vezes, jurídicas - para desqualificar certas acusações de racismo, homofobia, machismo etc. E, como a base do stand-up é o texto verbal, a linguagem se volta para uma tendência do humor americano e mundial, ou seja, para o politicamente incorreto (OLIVETTO, 2003, p. 33).

Com base em Possenti (1995, p. 125-129), podemos dizer que uma linguagem politicamente incorreta é perceptível a partir de formas linguísticas que veiculam, com maior ênfase, ideias de segregação de classe, de raça, de sexo etc. Nessa linha de raciocínio, a utilização dessa linguagem pode acarretar, entre outras coisas: i) tornar o vocabulário de determinada língua marcado em relação a qualquer grupo descriminado (por exemplo, negro, gay, sapatão, gordo, bicha etc.); e ii) fazer com que os sujeitos produtores de práticas discursivas que utilizam, consciente ou inconscientemente, essa linguagem sejam julgados como preconceituosos (machistas, homofóbicos, racistas...) a partir dos efeitos de sentidos que possam ser depreendidos na/pela enunciação de tal vocabulário.

Numa tentativa de reverter essa situação, os partidários de uma linguagem politicamente correta, conforme explica Possenti (1995, p. 131; 138), acabam caindo, do ponto de vista linguístico, em erros banais, como, verba gratia, propor a substituição do termo marcado por outro - teoricamente, não marcado -, pois se "considera que a troca de palavras marcadas por palavras não marcadas ideologicamente pode produzir a diminuição dos preconceitos"; entretanto, se o preconceito existe, é somente porque a sociedade gera condições para que o preconceito e os discursos que o justificam aconteçam. A reboque dessa substituição, se segue, muitas vezes, a inexistência na língua de um termo sinônimo, criando, como sugere Possenti (1995, p. 139), "eufemismos de certa forma cômicos, ou verdadeiras definições", como, por exemplo, "indivíduo casado com atividade sexual paralela" e "prestadora de serviços sexuais" em vez de adúltero e de prostituta, respectivamente. Ou seja, o politicamente correto se torna politicamente incorreto dependendo da visada impressa no enunciado pelo sujeito:

\begin{abstract}
Oh, desculpa! Eu não sei fazê esse negócio de stand-up... Tô meio nervoso, não tô acostumado a falá no microfone; na verdade, tô aqui só para cumprir a cota de negro no elenco... Queria fazê um protesto: que é muito difícil ser negro no Brasil, é muito difícil ser negro nesse País; tem país que mais fácil você ser negro... Tipo, sei lá: Nigéria, Angola... Uh, hu! Lá só dá nóis! Mas aqui é muito preconceito contra o negro. Negro, não! Que agora mudou, vocês tão sabendo? Agora, não pode mais chamar o coleguinha de negro, de preto; agora vocês são obrigados a me chamar de? [“Afrodescendente!" - responde a plateia] É... agora $\operatorname{sim} . .$. é um puta respeito comigo, cara. Eu passo na rua e as pessoas falam: "Afrodescendente, só faz merda hein!",18
\end{abstract}

No caso do $\mathrm{DH}$, para além do uso restrito de um vocabulário, a cultura do standup, com toda sua liberdade discursiva, e a linguagem politicamente incorreta, confusamente cerceada pelo politicamente correto, influenciam a própria estrutura dos gêneros do humor e a posição do humorista e dos demais sujeitos do riso dentro da

\footnotetext{
${ }^{18}$ Comedy Central Apresenta Stand-up com Marcelo Marrom. Disponível em: <https://www.youtube. com/watch?v=014FjRwzFFk>. Acesso em: 14 mar. 2013.
} 
sociedade. Isso porque, numa sociedade midiatizada como a nossa, mesmo os humoristas acreditando que estão "protegidos" pela condição de espetáculo do stand-up restrito ao teatro, ao cinema, às casas noturnas... seus enunciados politicamente incorretos acabam, por vezes, "vazando" para a mídia aberta (TV, rádio, jornais, internet etc.) em forma de discurso relatado (direto livre, indireto, indireto livre). Com efeito, o que se pode perceber é que, nessa situação, certos humoristas, de forma mais ou menos premeditada, fazem dessa reutilização de seus enunciados estratégias discursivas. Essas estratégias, além de os manter em evidência no cenário humorístico nacional, fazem deles alvos de interesses comerciais de grandes marcas e corporações nacionais e internacionais. Vejamos.

TAS: - Gente, que bunitinha que tá a Wanessa Camargo, grávida... isso...

RAFINHA BASTOS: - Comeria ela e o bebê!

TAS: - Mas... que isso?

RAFINHA BASTOS: - Tô nem aí! Tô nem aí!

TAS: - Aliás, esse bebê vai ser sortudo... Esse bebê vai ser acalentado por vozes...

RAFINHA BASTOS: - Ah, de cantores da família... Mas tá aí um bebê que vai durmir rápido. Os cara chega pra ele e diz assim: "Ou você dorme agora, ou a gente vai cantá... É o Zezé de Camargo... Ó! ${ }^{19}$

O excerto acima é um fragmento do programa humorístico CQC, exibido em horário nobre (22h) na Rede Bandeirantes de TV. Formato importado da Argentina, esse programa é liderado por Marcelo Tas que recruta, no cenário nacional, outros humoristas para compor uma equipe em prol de um humor moderno que a crítica, atualmente, considera como inteligente. Numa bancada, os principais do programa (sempre Tas e mais dois humoristas reconhecidos) comentam e criticam os principais fatos do País e do Mundo, da TV e do entretenimento. No entanto, a edição do dia 29 de setembro de 2011 ficaria conhecida como a última da qual Rafinha Bastos participaria.

Humorista do meio stand-up, Rafinha Bastos, antes mesmo do enunciado "comeria ela e o bebê", já era considerado um dos novos humoristas mais polêmicos e também mais bem sucedidos do Brasil, lotando shows por onde passava. Alvo de processos pelos membros da família Camargo, Rafinha foi obrigado a deixar o programa CQC, uma vez que pessoas influentes intervieram perante a diretoria da Rede Bandeirantes, pedindo sua "cabeça" pelo "caco" de enunciado politicamente incorreto (cf. XAVIER, 2011). Todavia, o que parecia ser o fim para Rafinha, se mostrou o início de uma rentável estratégia (discursiva) para angariar fundos para esse bobo da corte moderno.

Poucos meses depois de deixar a Rede Bandeirante, Rafinha assina um contrato milionário com o canal por assinatura FX (filiado à americana FOX ENTERTAINMENT GROUP) no qual o humorista transforma em "piada" os próprios problemas com a arte da comédia, principalmente seus processos na justiça e seus desafetos declarados. Para

\footnotetext{
${ }^{19}$ Fragmento do programa CQC. Disponível em: <https://www.youtube.com/watch?v=41THTgLWYDc $>$. Acesso em: 24 nov. 2012
} 
termos uma ideia de como funciona o programa, o teaser ${ }^{20}$ promocional de $A$ vida de Rafinha Bastos se mostra providencial. Nesse teaser, são apresentados, dentro de um elevador, uma grávida (sósia da cantora Wanessa Camargo) e o humorista, ambos em silêncio. Quase mortal para a pseudo Wanessa, o silêncio cria uma tensão, um mal-estar, enquanto o elevador vai subindo os andares. No nosso modo de ver, a instauração do silêncio no teaser é significativo, pois, como assevera Mello (2002, p. 87-88), o silêncio "fala tanto ou mais que as palavras, tornando-se uma forma estratégica de expressão e até mesmo uma tática de comportamento deliberado". Ou seja, além de mostrar o desconforto que o enunciado de Rafinha causou a todas as mulheres grávidas do País, a presença do silêncio no teaser ganha função de estratégia discursiva: a ausência de enunciado é uma forma de remissão não somente ao "comeria ela e o bebê", mas também a toda repercussão gerada com esse enunciado.

Voltando às "artimanhas" de Rafinha (sátiro) Bastos, podemos dizer que elas vão muito mais além. Considerado um dos "twiteiros" mais influentes do Mundo pelo New York Times (cf. HONORATO, 2011), Rafinha Bastos faz de seu Facebook e do seu microblog uma arma contra tudo e contra todos. Por exemplo, diante do caso de um apresentador da Rede Globo de TV pego em uma blitz policial contra o uso de álcool na direção, Rafinha diz:

Luciano, você bebeu antes de dirigir. Fez merda. Mas não se preocupe: Para a maioria do país, comunicador FDP não é aquele coloca a vida dos outros em risco, é aquele que fala o que pensa. Fique tranquilo. No fundo você está pensando: "Só bebi um pouquinho e estava a $20 \mathrm{Km} / \mathrm{h}^{, 21}$

Rafinha, entretanto, parece saber da repercussão de qualquer palavra que emite e, rapidamente, no seu Twitter pede "desculpas" ao apresentador:

\begin{abstract}
Li e reli o meu post anterior e decidi escrever. Personifiquei a minha ira contra a hipocrisia do planeta na figura do Luciano Huck. Fiquei indignado ao saber que o caso poderia morrer com uma simples "nota para a imprensa", mas não sou eu o responsável por puni-lo. A princípio, existe Justiça pra isso. Dirigir alcoolizado é um crime grave e este deveria ser o tema do meu post. Acabei transformando o caso em um palanque para despejar uma série de ofensas pessoais contra o trabalho do apresentador. Atitude desnecessária. Feia. Eu poderia ter exposto a minha opinião de uma forma muito mais inteligente e eficiente. Não sei se haverá algum processo judicial contra mim. Não é esta a questão. Estou aqui apenas para deixar claro que desta vez sinto que me equivoquei. Errei e por isso peço desculpas. PS1: Se você trabalha em um jornal ou portal e pretende reproduzir este texto, peço que o faça na íntegra (inclusive com os PSs). PS 2: Aproveito a oportunidade para avisar a todos que estou vendendo uma moto $250 \mathrm{cc}$ por apenas R \$ 5.500. Excelente estado. Tratar aqui. PS 3: Votem na Amanda França para a Menina Fantástica e votem para eliminar a Ísis na Fazenda de Verão. Ela só chora e não ajuda no dia-a-dia da casa. ${ }^{22}$
\end{abstract}

20 A vida de Rafinha Bastos. Teaser disponível em: <https://www.youtube.com/watch?v= BypSDjFElQs>. Acesso em: 5 maio 2013.

${ }^{21}$ Disponível em: $<$ http://contigo.abril.com.br/noticias/rafinha-bastos-critica-luciano-huck-por-se-recusarao-teste-do-bafometro>. Acesso em: 29 maio 2013.

${ }^{22}$ Disponível em: <http://ego.globo.com/famosos/noticia/2012/12/rafinha-bastos-pede-desculpas-lucianohuck.html>. Acesso em: 13 mar. 2013 
Não entraremos na querela entre Rafinha Bastos e Luciano Huck. O que nos interessa aqui é mostrar que, para além de representar uma pitada de chocarrice no pseudo pedido de desculpas, os PSs de Rafinha nos indicam mais uma de suas estratégias: a venda de caracteres do seu Twitter. De acordo com Honorato (2011), Rafinha comercializava, até 4 de maio de 2011, um Twitter (140 caracteres) patrocinado por, aproximadamente, $\mathrm{R} \$ 6.400,00$, contabilizando, para cerca de 2 milhões de seguidores, o valor de $\mathrm{R} \$ 0,03$ para cada caractere. Ou seja, o bobo mais uma vez mostra que de bobo não tem nada: utiliza a repercussão negativa do seu discurso em prol de um objetivo financeiro. Finalidade, aliás, que indica uma nova característica do DH encontrada por essa nova geração de humoristas.

Como sabemos, os atos de comunicação humorísticos podem ser utilizados por outros tipos de discurso enquanto estratégia discursiva (cf. CHARAUDEAU, 2006a), principalmente na literatura e na publicidade. Nesses termos, os atos de comunicação humorísticos (doravante, ACHs) atravessam esses discursos e, por vezes, chegam a ser considerados uma característica essencial de alguns gêneros como, por exemplo, nas propagandas. Todavia, com a "sombra" do politicamente correto pairando sobre vários temas, o que está acontecendo com alguns formatos de humor é exatamente o contrário: atos de comunicação de natureza publicitária estão atravessando os gêneros específicos do humor, numa espécie de marketing que, pelas similitudes de processo e pela presença da linguagem politicamente incorreta, denominamos, ad hoc, de marketing pelo método confuso. Expliquemos.

$\mathrm{Na}$ publicidade, o ataque direto a marcas concorrentes que produzem e/ou comercializam um mesmo produto no mercado é tido, normalmente, como uma prática discursiva falha e, atualmente, também como um ato politicamente incorreto. Isso porque, tal prática pode, entre outras coisas, funcionar de modo contrário, dando maior visibilidade ao produto da marca concorrente. No caso do marketing pelo método confuso (doravante, MMC), o humorista, vendo seu discurso, na maioria das vezes, talhado pelas coerções sociodiscursivas do politicamente correto a favor das minorias, encontra, na "guerra" entre as empresas e suas marcas, espaço para fazer humor e, ao mesmo tempo, para ganhar dinheiro, como, por exemplo, o que acontece em vários sketches humorísticos do canal Portas dos Fundos do Youtube (https://www.youtube. com/user/portadosfundos).

Com programas de curta duração (de 2 a 5 minutos), o grupo de humoristas liderado por Antônio Tabet representa situações do dia a dia que acabam declinando ora para um humor inteligente com toques de nonsense, ora para um cômico próximo do grotesco sexual. Sucesso na internet, o Porta dos Fundos chamou a atenção dos diretores de marketing que, em tempos de redes sociais, entenderam que "não adianta tentar abafar críticas ou dar respostas evasivas ao público: as marcas devem entrar no jogo com transparência; melhor ainda se for com bom humor" (cf. TABET, 2013, p. 15). Isso porque, em vários episódios do Porta dos Fundos, as empresas que esses diretores representam foram, de algum modo, ridicularizadas pelo MMC, como, por exemplo, no episódio 3. A cena se passa em um restaurante. Um casal está conversado, quando: 
RAPAZ: - Ei, garçom, você me vê uma Coca, por favor!

GARÇOM: - Ih! Só tem Pepsi, pode ser?

RAPAZ: - Neeeeão... não! ${ }^{23}$

Aqui, o que se esperava era uma confirmação do enunciado do garçom com a resposta "Pode!", ao que se seguiria uma surpresa agradável (do tipo: duas mulheres esperando o rapaz na cama; ou o jogador Ganso, fenômeno da Seleção Brasileira, entrando no time da pelada do bairro do rapaz etc.) e o slogan da marca: "pode ser bom... pode ser muito bom... pode ser Pepsi!". Como se vê, o humor é estabelecido pela negação da publicidade da Pepsi que, no mercado brasileiro, não alcança as marcas de vendagem da concorrente.

Em outro episódio intitulado $\mathrm{Na} \mathrm{lata}^{24}$, a zombaria se volta, ao mesmo tempo, para a promoção da marca Coca-Cola que viabilizou, na lata dos refrigerantes, nomes próprios aleatórios como meio de aproximar a marca dos seus consumidores, e para uma marca nacional de refrigerantes de qualidade inferior (conhecidos como "refrigerecos"), mas de grande sucesso entre as classes mais populares devido ao menor preço do produto em comparação com as grandes marcas internacionais. Nesse episódio, uma consumidora com roupas decotadas procura seu nome na lata da Coca. Vendo a moça nessa situação, um auxiliar de supermercado oferece ajuda:

\author{
AuXILIAR DE SUPERMERCADO: - Opa! Tudo Bem! Quer alguma ajuda, tá procurando \\ alguma coisa, quer alguma ajuda...? \\ CONSUMIDORA: — sim, tô procurando meu nome na latinha. \\ AUXILIAR DE SUPERMERCADO: - Ah, legal! Qual é seu nome? \\ CONSUMIDORA: — É Kelen? \\ AUXILIAR DE SUPERMERCADO: - Kelen... não... Kelen é ruim. É um nome merda, não tem. \\ CONSUMIDORA: Como assim? \\ AuXILIAR DE SUPERMERCADO: - Nome de puta, a Coca não faz... Brigite, Sheila... eu
} nunca vi.

CONSUMIDORA: - Você tá louco, tá maluco?

AUXILIAR DE SUPERMERCADO: - Ah tá, Kelen é legal? Kelen agora é um "puta” nome? Kelen é um nome bíblico? A mãe é de Cristo, Kelen! Kelen é ruim. Meu nome é Welerson e não é por isso que estou procurando, aqui, meu nome na latinha. Meu nome é bosta e eu tenho consciência disso...

CONSUMIDORA: - Ok, Welerson. Mas eu já achei Kely. Então, se tem Kely, de repente tem meu nome..

AUXILIAR DE SUPERMERCADO: - Kely é um nome; Kelen é a derivação merda desse nome... é ruim. Por duas letras, seu pai te amaldiçoou pra sempre.

CONSUMIDORA: - Tá bom, obrigada, eu vou continuar procurando porque eu sei que eu vou achar.

AUXILIAR DE SUPERMERCADO: - Não, você não vai achar... Se quiser achar, você procura na promoção aqui em baixo, que é a promoção do Doly, que é bem semelhante, só que com nome merda: Pamela... ó, tem Tabata... tem nome errado, tem "Cráudio"... tem um que eu gosto muito que é "Grória" (lembrei do nome da minha mãe...). Agora, se você não achar no Doly, acho que a promoção da Sukita... é a tua onda!

\footnotetext{
${ }^{23}$ Disponível em: <http://www.youtube.com/watch?v=B0M_pRh2hNw>. Acesso em: 24 maio 2013.

${ }^{24}$ Disponível em: <http://www.youtube.com/watch?v=NZb0XKHgtjo>. Acesso em: 24 maio 2013.
} 
Diferentemente do episódio 3, Na lata mostra que não há partidarismos, como poderia parecer: tanto a Coca como o Doly, a Pepsi e a Sukita e, também, seus respectivos consumidores são, todos, "esculhambados", ridicularizados. No entanto, o que poderia gerar processos legais como o que acontece com os humoristas stand-up, no caso do Porta dos Fundos, aparece como uma fórmula de marketing - confuso - que as empresas e as corporações veem como um novo espaço (humorístico cibernético) para divulgação de suas marcas do qual elas não podem, por isso mesmo, se privar.

\section{CONSIDERAÇÕES FINAIS}

Pelas razões aduzidas, somos levados a: i) afirmar que o humor não é somente uma característica estilística ou uma estratégia discursiva à disposição de certos escritores, mas também uma máscara capaz de marcar o lugar - e em alguns casos o destino (como, por exemplo, o de Mendes Fradique), dentro de um determinado campo discursivo, daqueles que se aventuram pelo universo do riso e do risível; ii) assumir que o campo do humor, assim como alguns campos discursivos (por exemplo, o literário), é extremamente sensível às mudanças sociais, discursivas e tecnológicas, ou seja, o DH acompanha de perto os outros tipos de discursos, os meios de circulação desses tipos e as ações justificadas por esses discursos (cf. politicamente correto) dentro de uma dada sociedade de modo a poder tirar proveito, a favor do riso, das contradições inerentes a cada um deles; e, por fim mas não menos importante, iii) admitir que o MMC vem ao encontro da nossa ideia de que o DH realmente pode ser considerado um tipo de discurso, nos mesmos moldes do discurso político ou do discurso literário, uma vez que por meio do MMC podemos colocar em evidência que não é o humor que funciona em prol da publicidade, mas que é a publicidade que passa a constituir matéria, substância para o humor enquanto discurso.

\section{REFERÊNCIAS}

AUBERT, A. C. Piada de português? Trip, São Paulo, n. 221, maio, p. 104, 2013.

BOSI, A. História concisa da literatura brasileira. 48. ed. São Paulo: Cultrix, 2012.

BUSATTO, L. Posfácio: M. F. e sua gramática. In: FRADIQUE, M. Grammatica portugueza pelo methodo confuso: adoptado em todas as escolas primarias, secundarias e terciarias do Brasil e suburbios. 3. ed. Rio de Janeiro: Rocco, 1984, p. 273-274.

CANDIDO, A. Literatura e sociedade. 9. ed. Rio de Janeiro: Editora Ouro Azul, 2006.

CHARAUDEAU, P. Des catégories pour l'humour. Questions de Communication: humour et média. Définitions, genres et cultures. Nancy, n. 10, p. 27-43, 2006a. Discurso Político. São Paulo: Contexto, $2006 \mathrm{~b}$.

ESCARPIT, R. L'humour. 5. ed. Paris: Presse Universitaires de France, 1972.

FRADIQUE, M. Desvantagens do methodo confuso. In: A lógica do absurdo. Rio de Janeiro: Editora Leite Ribeiro, 1925.

História do Brasil pelo método confuso. São Paulo: Companhia das Letras, 2004.

GARCIA, O. M. Comunicação em prosa moderna: aprenda a escrever, aprendendo a pensar. 27. ed. Rio de Janeiro: Editora FGV, 2010.

GENTILI, D. Irreverência. Jornal Pampulha: o semanário de Belo Horizonte. Belo Horizonte, n. 1144, 30 jun. 2012. 
HAMA, L. Maluf, o senhor é ladrão? Trip. São Paulo, n. 221, maio, p. 96-101, 2013.

HONORATO, R. Campeões de audiência no twitter vendem de tudo na rede. Veja São Paulo (edição online). Editora Abril, maio, 2011. Disponível em: <http://veja.

abril.com.br/noticia/vida-digital/campeoes-de-audiencia-do-twitter-vendem-de-tudo-na-rede\#texto1>. Acesso em: 28 maio 2013.

LUSTOSA, I. Brasil pelo método confuso: humor e boemia em Mendes Fradique. Rio de Janeiro: Bertrand Brasil, 1993.

. Introdução à História do Brasil pelo método confuso. In: FRADIQUE, M. História do Brasil pelo método confuso. São Paulo: Companhia das Letras, 2004. p. 9-25.

MACHADO, A. A. Cavaquinho e saxofone (solos). Rio de Janeiro: José Olympio, 1940.

MAINGUENEAU, L. L'analyse des discours constituants. In: MARI, H. et al. (Org.) Fundamentos e dimensões da análise do discurso. Belo Horizonte: Carol Borges-NAD/FALE/UFMG, 1999, p. 45-58.

Doze conceitos em análise do discurso. São Paulo: Parábola Editorial, 2010.

MARTINHO, T. Tá rindo do quê? Trip. São Paulo, n. 221, maio, p. 58-65, 2013.

MASUCCI, F. Dicionário humorístico. 2. ed. São Paulo: Editora Leya, 1958.

MELLO, R. Análise discursiva do(s) silêncio(s) no texto literário. In: MACHADO, I. L. et al. Ensaios em análise do discurso. Belo Horizonte: FALE/UFMG, 2002. p.87-123.

MENDONÇA, M. A stand-up comedy vira sucesso no Brasil. Época (on-line), n. 469, jul. 2007.

Disponível em: <http://revistaepoca.globo.com/Revista/Epoca/0; EDG77345-6006;00.html >. Acesso em: 29 maio 2013.

MENNUCCI, S. Húmor. São Paulo: Monteiro Lobato \& Cia. Editores, 1923.

MINOIS, G. História do riso e do escárnio. São Paulo: Editora UNESP, 2003.

OLIVETTO, W. Uma conversa séria sobre humor. Favor não ri. In: FEDRIZZI, A. (Org.) O humor abre corações. E bolsos. Rio de Janeiro: Campus, 2003, p. 29-61.

PINTO, Z. A. Ninguém entende de humor. Revista de Cultura Vozes, Rio de Janeiro, n. 3, vol. LXIV, p. 21-37, 1970.

PIRANDELLO, L. O humorismo. São Paulo: Experimento, 1996.

PONDÉ, L. F. Guia politicamente incorreto da filosofia. São Paulo: Leya, 2012.

POSSENTI, S. A linguagem politicamente correta e a análise do discurso. Revista Estudos da Linguagem. Belo Horizonte, ano 4, v. 2, jul./dez. p. 123-140, 1995. Disponível em:

$<$ http://www.periodicos.letras.ufmg.br/index.php/relin/article/view/1016/1127>. Acesso em: 24 maio 2013.

S. Humor, língua e discurso. São Paulo: Contexto, 2010.

SALIBA, E. T. Raízes do riso: a representação humorística na história brasileira. São Paulo: Companhia das Letras, 2002.

SANTOS, R. E. Reflexões teóricas sobre o humor e o riso na arte e nas mídias massivas. In: SANTOS, R. E.; ROSSETTI, R. (Org.) Humor e riso na cultura midiática: variações e permanências. São Paulo: Paulinas, 2012. p. 17-59.

SKINNER, Q. Hobbes e a teoria clássica do riso. São Leopoldo: Editora UNISINOS, 2002.

SOARES, J. Se não tem graça, piada vira grossura. Folha de S.Paulo (edição on-line). São Paulo, out. 2011. Disponível em: <http://www1.folha.

uol.com.br/fsp/ilustrad/fq2210201111.htm>. Acesso em: 01 abr. 2012.

TABET, A. Saída pelos fundos. Trip, São Paulo, n. 221, maio 2013.

TIGRE, B. Versos perversos: poesias satyricas em comentário aos acontecimentos de 1904. Rio de Janeiro: Livraria Cruz Coutinho, 1905.

VALE, R. P. G. Perde a piada; a vrbanitas, não! - A linguagem do riso na constituição do ethos discursivo. Entremeios (On-line), v. 3, 2011.

VERISSIMO, L. F. Amor nos tempos de comédia. Trip, São Paulo, n. 221, p. 40, maio 2013.

XAVIER, M. Rafinha bastos, o novo rei da baixaria. Veja São Paulo (edição on-line), out. 2011.

Disponível em: <http://vejasp.abril.com.br/materia/rafinha-bastos-comediante-acha-engracado $>$. Acesso em: 11 jun. 2012. 
Recebido em: 12/05/15. Aprovado em: 23/07/15.

Title: Humor, comedians and discursive topia problems

Author: Rony Petterson Gomes do Vale

Abstract: Based on the concept of discursive field and History of humor, we seek to outline the way the humor from literature leading to its institutionalization as discursive field of the humor. We seek to show, firstly, how the humor changes from stylistic feature of some writers and poets to some regulation of comedian profession next to the fields journalism and advertising fields. Secondly, we find that the concept of VRBANITAS, which regulates the use of laughter in the discourse, can be seen from the position of disputes between subjects within the discursive field of humor, which differ according to the concept adopted on what do humor and make laugh, and modes of adaptation to the constant social changes, new forms of media and the politically correct movement.

Keywords: Brazilian humor. Discursive fields. Discourse analysis. Confusing method. Politically correct.

Título: Humor, humoristas y problemas de topia discursiva

Autor: Rony Petterson Gomes do Vale

Resumen: Partiendo del concepto de campo discursivo y de la historia del humorismo, trazamos, en líneas generales, el camino del humor de las entrelíneas de la literatura para su institucionalización mientas campo del humor. Procuramos evidenciar, primeramente, cómo el humor pasa de característica estilística de algunos escritores y poetas para una cierta reglamentación de la profesión de humorista junto a los campos del periodismo y de la publicidad. En un segundo momento, verificamos que el concepto de VRBANITAS, que reglamenta los usos de la risa en el discurso, puede ser percibido desde las disputas de posicionamiento entre los sujetos dentro del campo del humor, que se diferencian de acuerdo con la concepción adoptada sobre que es hacer humor y hacer reir, y con los modos de adaptación a los constantes cambios sociales, las nuevas formas de medias y al movimiento politicamente correcto.

Palabras-clave: Humorismo brasileño. Campos discursivos. Análisis del discurso. Método confuso. Políticamente correcto. 